\title{
A qualitative exploration of prostate cancer survivors experiencing psychological distress: Loss of self, function, connection, and control
}

Dr Lauren Matheson ${ }^{1}$, Dr Jo Nayoan ${ }^{2 *}$, Dr Carol Rivas ${ }^{2 * *}$, Dr Jo Brett ${ }^{1}$, Dr Penny Wright ${ }^{3}$, Mr Hugh Butcher $^{4}$, Dr Anna Gavin ${ }^{5}$, Professor Adam Glaser ${ }^{36}$, Professor Eila Watson ${ }^{1} \&$ Dr Richard Wagland ${ }^{2}$ (joint last two authors)

\section{Affiliations}

10xford Institute of Nursing, Midwifery and Allied Health Research, Oxford Brookes University, Marston road, Oxford, OX3 OFL

${ }^{2}$ Faculty of Health Sciences, Building 67, Highfield, Southampton, SO17 1BJ, UK

${ }^{3}$ Leeds Institute of Cancer and Pathology, University of Leeds, LS2 9JT, UK

${ }^{4}$ LAPCD patient user advisory group, UK

${ }^{5}$ Northern Ireland Cancer Registry, Centre for Public Health, Queen's University Belfast, Mulhouse Building, Grosvenor Road, Belfast BT12 6BJ, UK

${ }^{6}$ Leeds Institute of Data Analytics, University of Leeds, Leeds, LS2 9JT, UK

$*_{\text {for authors whose current address is different }}$

* European Centre for Environment and Human Health (ECEHH), University of Exeter, Knowledge Spa, Truro TR1 3HD

**Department of Social Science, University College London (UCL), 18 Woburn Square, London WC1H ONR, UK

Key words: Patient experience, distress, prostate cancer, psychological, qualitative, health care 


\section{Abstract}

Purpose: To explore the experiences of men with prostate cancer identified as having psychological distress and to identify factors influencing distress.

Participants and setting: 28 men with prostate cancer diagnosed 18-42 months earlier, identified as having psychological distress on survey measures.

Methodologic approach: Semi-structured telephone interviews were conducted. Thematic analysis using a Framework approach was used.

Findings: Men with psychological distress had strong perceptions of 'loss' towards a) self (identity, sexuality/masculinity, self-confidence), b) function (physical, activities), c) connection (relational, social, community) and d) control (future, emotional). Psychological vulnerability appeared heightened in particular groups of men. Maladaptive strategies of emotional concealment, helpseeking avoidance and withdrawal appeared to contribute to distress.

Implications for nursing: Distress in men with prostate cancer is multifaceted. Men with distress should be identified and offered support. Nursing and/or peer-led interventions are required.

\section{Knowledge Translation:}

1. A significant minority of men with prostate cancer report distress $18-42$ months following diagnosis. Screening tools for psychological difficulties may help identify men in need of further support.

2. The author's conceptual model highlights pre-existing and treatment related factors, as well as maladaptive coping strategies influencing distress. Greater support with restoring selfidentity and confidence is needed.

3. Nurse-led patient education and information on managing psychological and physical concerns, as well as sign-posting to peer support, community or online support groups is required.

\section{Introduction}

Prostate cancer ( $\mathrm{PCa}$ ) is currently the second most common cancer amongst men worldwide (Bray et al., 2018). Although survival rates are high (Allemani et al., 2015), PCa and its treatments can negatively impact on quality of life (Punnen, Cowan, Chan, Carroll, \& Cooperberg, 2015; Watson et al., 2016). In the United Kingdom (UK), the setting for this study, men with localised PCa are commonly offered a choice of treatments, including radical prostatectomy, external beam radiotherapy, brachytherapy, androgen deprivation therapy (ADT), active surveillance, or a combination of these (National Institute For Health and Care Excellence, 2019). Men with advanced PCa may be offered hormonal therapy, watchful waiting or chemotherapy. There is currently no UK PCa screening program, however men with family history or symptoms are offered a prostate specific antigen (PSA) test and digital rectal examination.

Treatments can significantly impact on sexual, urinary and bowel functioning, and may also lead to fatigue, weight gain, hot flushes, loss of muscle mass and emotional instability (Blomberg et al., 
2016; Punnen et al., 2015; Watson et al., 2016). Meta analyses of previous studies suggest that in men with PCa, rates of depression and anxiety post treatment are $18.4 \%$ and $18.5 \%$ respectively (range 15\%-27\% across the treatment spectrum), (Watts et al., 2014); these are significantly greater than in the general population. Men are also at increased risk of suicide after PCa diagnosis, particularly men who are older, unpartnered, white or with metastatic disease (Klaassen et al., 2015; van Leeuwen \& Schröder, 2010). While most men with PCa report good overall health-related quality of life (Downing et al., 2018), some report unmet psychological needs, and lower satisfaction with psychosocial aspects of their health care (Paterson, Kata, Nandwani, Chaudhury, \& Nabi, 2017; Watson et al., 2016). Men have reported that their current healthcare does not provide a holistic person-centred model of care (Paterson, Kata, Nandwani, Chaudhury, \& Nabi, 2017).

Treatment side effects can negatively impact on masculinity and cause dissatisfaction over body feminisation (Ervik, Nordoy, \& Asplund, 2010; Gentili et al., 2019; O'Shaughnessy, Ireland, Pelentsov, Thomas, \& Esterman, 2014; Schildmeijer, Frykholm, Kneck, \& Ekstedt, 2019; Stapleton \& Pattison, 2015). Men might also encounter many PCa-related uncertainties, as well as distress related to embarrassment and sense of stigma associated with side effects (Matheson et al., 2017; Rivas et al., Submitted). Men who are younger, unpartnered, gay or from Black and Minority Ethic (BME) groups may be particularly vulnerable to these effects (Matheson et al., 2017; Rivas et al., 2016). Men with advanced cancer, men on combination treatments or ADT are at increased risk of social and psychological distress and report more cancer-related symptoms, compared to men on other treatments (Wilding et al., 2019; Wright et al., 2019). Meta-analysis has also shown that men on ADT have a $41 \%$ increase risk of depression (Nead, Sinha, Yang, \& Nguyen, 2017). In men on ADT, clinically significant levels of fatigue has been strongly associated with psychological distress (Wilding et al., 2019). However, what is lacking in the literature is a more nuanced understanding of how men with PCa experience psychological distress and what contributes to their distress. This is needed in order to develop interventions to improve the support provided to men in the future.

Research shows that, worldwide, men are particularly vulnerable to severe distress with older men (over 70 years) from higher-income countries most likely to die of suicide (Fung \& Chan, 2011; World Health Organisation, 2014). Men are also less likely than women to seek professional help for psychological distress, as men may be unwilling to admit psychological problems (Bilsker, Fogarty, \& Wakefield, 2018; McCaughan, Prue, Parahoo, Mcllfatrick, \& McKenna, 2011). This may be influenced by traditional masculine ideals of self-reliance, independence and stoicism (Bilsker et al., 2018; Cecil, Mc Caughan, \& Parahoo, 2010). Qualitative research indicates that men may come across to health professionals as 'confident and coping', yet they may be hiding a significant emotional burden (Stapleton \& Pattison, 2015). The importance of designing gender-appropriate interventions that specifically address men's distress and provide an emotional outlet has therefore been highlighted (Bilsker et al., 2018; Stapleton \& Pattison, 2015; Wenger, Oliffe, \& Bottorff, 2014). A previous metasynthesis has highlighted coping strategies that men with PCa employ (Spendelow, Eli Joubert, Lee, \& Fairhurst, 2017), although much of the evidence relates to adaptive coping strategies involved in adjustment. Our meta-synthesis of qualitative studies $(n=133)$ highlighted the often gendered ways that men dealt with the emotional impacts of PCa (Rivas et al., Submitted). However, studies generally included men with varying degrees of psychological wellbeing, and no studies specifically explored a subgroup of men with distress, particularly how these men might be supported better (Rivas et al., Submitted). 
Distress and wellbeing in individuals with cancer has been associated with illness perceptions and coping behaviours (Leventhal, Phillips, \& Burns, 2016; Richardson, Schüz, Sanderson, Scott, \& Schüz, 2017). According to illness perceptions theory, perceiving the illness as controllable or with few consequences is associated with lower distress and better wellbeing (Leventhal et al., 2016; Richardson et al., 2017). However, the role of individuals' perceptions and coping strategies in relation to distress in men with PCa requires greater attention and is the focus of this paper. Little is known about the coping strategies of men with PCa who exhibit distress, so exploring this would highlight how support for men might be optimised, such as through interventions and clinical practice. Our data come from the Life After Prostate Cancer Diagnosis (LAPCD) study, a UK population-based mixed methods study (Downing et al., 2016), that aimed to explore the physical and psychosocial impact of PCa through a survey and interviews. In this qualitative sub-analysis we specifically explore the experiences of men identified as having psychological distress, drawn from the total sample of interviewed men with PCa. We aimed to inform how support for these men could be optimised and explore the factors influencing distress.

\section{Methods}

\section{Ethics}

Ethical and regulatory approvals were obtained from Newcastle/North Tyneside Research Ethics Committee (15/NE/0036), Health Research Authority Confidentiality Advisory Group (15/CAG/0110), NHS Scotland Public Benefit and Privacy Panel (0516-0364), Northern Ireland Research Ethics Office (16/NI/0073). Informed consent was obtained from all interview participants.

\section{Design}

Full methodological details of the LAPCD study have been published (Downing et al., 2016). In brief, men diagnosed with PCa 18-42 months previously were invited to participate in a postal survey addressed to their home. Three cancer registries across England, Wales and Northern Ireland and hospital activity data in Scotland were used to identify men. Survey respondents indicated if they were willing to also be interviewed by phone. COREQ reporting guidelines were followed (Tong, Sainsbury, \& Craig, 2007).

\section{Data collection}

\section{Sampling}

Men consenting to interview were contacted following completion of the LAPCD survey. A purposive sampling framework was developed, to include men with different treatment types, and a range in terms of age, ethnicity and sexual orientation, as well as physical or psychological problems, as indicated by their survey responses. 149 men were interviewed. Data reported here came from a subsample $(n=28)$ of this larger interview dataset comprising all men who were identified as having psychological distress on one or both of the following validated measures of psychological distress from the LAPCD survey: the Short Warwick-Edinburgh Mental-Well-being Scale (SWEMWBS) (Stewart-Brown et al., 2009), and the six item version of the Kessler Psychological Distress Scale (K6) (Kessler et al., 2002). The SWEMWBS (Stewart-Brown et al., 2009) aims to measure psychological well-being, and the full version has been widely used in national surveys (National Statistics, 2017) and in cancer research (Clarke et al., 2019). Scores $\leq 19.25$ are suggested to indicate poor well-being ( $\mathrm{Ng}$, Kristjanson, \& Medigovich, 2006). The K6 is a measure that assesses non-specific psychological distress and has been used previously in individuals with cancer (Oba et al., 2017; Rim et al., 2019; 
Zhao, Li, Li, \& Balluz, 2013). A cut-off score of $\geq 19$ indicates severe psychological distress (Prochaska, Sung, Max, Shi, \& Ong, 2012).

\section{Interviews}

Semi-structured telephone interviews lasted one hour on average and were conducted by two postdoctoral (LM, JN) and two senior (RW, CR) health researchers. Interviewers came from broad disciplinary backgrounds including nursing, sociology and psychology, and included one male (RW). A comprehensive interview topic guide was developed (see Box 1) in collaboration with the LAPCD clinical and patient user advisory groups (UAG), and informed by our meta-syntheses of qualitative studies (Matheson et al., 2017; Rivas et al., Submitted; Rivas et al., 2016). Men were interviewed about the psychosocial and physical impact of $\mathrm{PCa}$, and their health care experiences. Questions were open-ended and researchers used prompts to encourage participants to expand upon answers.

\section{Analysis of interviews}

Interviews were recorded by a software program (Audacity) and transcribed verbatim. Sensitive or personal information was de-identified at the point of transcription. All data was stored in a secure University repository only accessible from a password protected computer. Thematic analysis, involving the seven stage Framework approach (Gale, Heath, Cameron, Rashid, \& Redwood, 2013) was undertaken for all interviewed men for the main LAPCD study. Following familiarisation, five initial transcripts were independently coded then discussed within the research team and the LAPCD patient UAG, as several user group members reviewed selected transcripts and provided feedback. A coding framework was developed as themes emerged (supplementary file 1). The framework was further developed and adapted following analysis of subsequent interviews and group discussion. Transcripts were uploaded and managed using Nvivo v.11 (QSR International Pty Ltd, 2016). Double coding in Nvivo was conducted (CR, EW and RW) on $10 \%$ of all interviews, with final Kappa scores of $\geq 80 \%$ across all themes for all researchers. All interview transcripts were indexed into the framework in Nvivo involving identification of each section of data that corresponded to each theme in the framework. Data were then summarised into coding summaries in the framework (JN, LM, CR, RW). Our analysis was rooted in a social constructivist paradigm.

Analysis of the subsample involved collation of the coding frameworks of all men with psychological distress, which were then examined across and between participants to explore within-group convergence and divergence in more detail (LM, JB, EW). The analysis was discussed at team meetings and with members of UAG. Through this process we were also able to consider the subsample within the context of the larger sample of interviewed participants. Data saturation was achieved. Socio-demographic and treatment information, as well as information on comorbidities (Table 1) was also obtained from the LAPCD survey as well as during interviews.

\section{Results}

The characteristics of the subsample of men $(n=28)$ with distress are shown in Table 1 . This subsample comprised $18.8 \%$ of the 149 men interviewed overall. 19/28 men had received ADT either alone $(n=8)$ or as an adjuvant treatment $(n=11)$. For the subsample of men with distress, two overarching themes are presented. 


\section{Theme 1: Perceptions of loss}

Men with psychological distress had strong perceptions of loss, relating to loss of function, connection, self and control, and displayed ongoing difficulties coping with these bodily and biographical disruptions. This theme of loss was also evident, but to a much lesser degree, in nondistressed men in the wider sample of all interviewed men ( $n=121 / 149)$, who often described acute yet largely transient distress around diagnosis.

\section{Perceptions regarding loss of function}

The severity of perceptions of loss in men in the distressed subsample regarding physical functioning varied depending on the type of treatment received and in a few cases, on stage of disease. A few were distressed if they had ongoing and severe unresolved problems regarding urinary or bowel functioning following surgery or radiotherapy, particularly if this significantly impacted on their daily activities. These problems were worrying and embarrassing to men, and could be a barrier to social participation. Some struggled to cope with changes to their sexual relationships following treatment, and in comparison with non-distressed men in the wider sample, struggled to use strategies such as acceptance and reappraisal that appeared adaptive. Holding strong values and expectations regarding traditional or hegemonic masculinity also seemed to influence distress, particularly regarding men's response to sexual dysfunction as well as the loss of physical strength and fitness.

It's just not right. It's the self-esteem, not feeling like a complete a man.. not just the sex side of things, it's the strength to do things. You're trying to lift things that you used to think nothing of before, and you can't do it anymore. Climbing mountains, you can't do that like you used to do. So it's all a bit tough really.. (60 years, married, stage IV)

However, sexual functioning was not a priority for all men, with some on ADT describing less bother over this issue, attributed by men to the ADT-related loss of libido. Men with advanced PCa reported distress over feeling socially and physically restricted by side effects, such as pain and fatigue and the subsequent immobility experienced.

\section{Perceptions regarding loss of self}

Men reported a strong sense of loss of self and identity changes which appeared to influence their distress. In those with substantial physical health problems, from advanced PCa and/or comorbidities, the loss of the active self was especially difficult to accept. Some men struggled with their declining ability to participate in valued activities such as work, walking or gardening and the transition to a more sedentary lifestyle. A loss of self-confidence was reported in their health, social or work situations. PCa also impacted on some men financially, who felt distress over being in debt or on a low income. Younger men in particular found this impact of PCa harder to accept and held concerns regarding their role as provider. Sexual dysfunction was common due to PCa treatment, and led to a sense of loss of the sexual and masculine self, which led men to report a loss of selfconfidence and feelings of failure and inadequacy ('no matter how understanding one's partner is...you still feel as though you've failed... you are no longer the man you thought you were' 69 years, married, stage I). ADT-related symptoms, such as breast enlargement, mood swings, and loss of muscle mass, also contributed to a sense of loss over the masculine self and some men felt ADT was the cause of their distress, due to the direct impact on mood. 
After the hormone treatment kicked in I had a change in personality. And I lost confidence in myself as a person, especially in the work that l'd been doing before that. And that has continued, so personality wise it's been a kick in the teeth (75 years, married, stage I)

\section{Perceptions regarding loss of connection}

Men held strong perceptions regarding a sense of loss of connection to others. A sense of loss over a much diminished social life was attributed to physical health limitations from PCa and/or comorbidities, a result of feeling depressed or due to lower self-confidence to engage in social activities.

The confidence hasn't come back. So life's quieter these days. I used to do a lot of. [theatre work]... and I've stopped doing that completely, because I don't have the confidence to do it anymore. So the social side of my life has diminished (75 years, married, stage I)

A few men felt they had lost friendships or become distant to friends, which was distressing. A loss of connection with their partners was reported by some men in this subsample, as they struggled with conflict or strain on their relationship. A few felt sexual problems had led to arguments or emotional distancing or, in one case, had directly led to relationship breakdown.

The relationship ended because basically I was told well because you can't perform [sexually], not interested, it's time to call it an end (54 years, single, stage III)

Being without a partner at diagnosis often exacerbated distress as men described loneliness dealing with PCa alone ('it has been a very lonely journey for me' - 58 years, widowed, stage I). Being unpartnered also contributed to distress and worry over potential future intimate relationships due to erectile dysfunction, and fears of rejection.

\section{Perceptions regarding loss of control}

Men held strong perceptions regarding a sense of loss of control caused by PCa, such as a lack of bodily control. Men receiving ADT felt this treatment contributed to the loss of emotional control they experienced ('it's just spontaneous. I just all of a sudden feel sad and want to cry'- 66 years, married, stage III). For a few men with advanced disease, this had led to suicidal thoughts ('I wanted to end my life. I was totally depressed with it all', 67 years, married, stage IV). Other men discussed a sense of loss of control over the future, and having to learn to live with greater uncertainty. Men often held negative perceptions towards cancer, regardless of their prognosis, such as feeling they had low control over PCa. Some struggled with controlling rumination over negative thoughts surrounding PCa and fears of recurrence, even despite having a good prognosis in some men ('it is purely this perpetual feeling that it could come back and haunt you...I try to shove it to one side. But it is there again...at the back of your mind' 69 years, married, stage I).

You've kind of lost your shield, and you do feel vulnerable. You say once it's happened to you once it can happen again (48 years, In relationship, stage I)

A few men felt that more emotional support from health professionals, particularly a little more time and reassurance during and in addition to follow-up appointments, would help alleviate anxiety. 
There doesn't seem to be any structure that will trigger somebody to ring the patient ...to say how are things going, do you need to talk or do you want chat about anything? (60 years, married, stage IV)

\section{Psychological vulnerability: exacerbating factors}

In addition to the factors already described, including younger age, being unpartnered, and having a high symptom burden, other factors also appeared to exacerbate distress. These related to preexisting psychological or physical issues. Pre-existing psychological problems, such as clinical depression or anxiety, prior to the PCa diagnosis was reported by some men ('I had a bit of depression before, but it's increased since' - 63 years, in a relationship, stage I), which for a few, were perceived as more of a problem than PCa related distress. Some also attributed personality traits as contributors to their distress, such as having anxious or depressive personalities or being pessimistic. Being treated with ADT $(n=19)$ rendered men with a particular vulnerability to be distressed ('I'm on antidepressants at the moment, because the [ADT] makes you down. It's made me more a worrier I think' 60 years, married, stage IV). Participants with multiple co-morbidities often felt they were more distressed about these other illnesses than PCa.

\section{Theme 2: Maladaptive strategies for coping with distress}

Some men in the subsample used strategies that helped them cope, including seeking professional support, taking anti-depressant medication and talking to partners and those in their social networks. However compared to the wider sample, the men in this subsample were more likely to use strategies that could be maladaptive.

\section{Concealment of distress}

Men commonly discussed concealing their distress from others and some put on a brave face for their families specifically. Some men attributed their behaviour to generational as well as gendered norms and ideals surrounding masculinity, including stoicism, self-reliance and emotional concealment ('we're old generation, so you don't talk about things' 60 years, married, stage IV). I have to watch my emotions at times, they can take over. I can walk around and look as tough as anybody, but inside I'm probably falling apart (67 years, married, stage IV)

\section{Avoidance of help-seeking}

Some men, avoided seeking professional help for distress, stating reasons such as: not wanting to take medication, not wanting to talk to or feel they were 'bothering' health professionals, dismissing talking therapies as a 'waste of time', a preference for talking to their partner or friends, or feeling they should be self-sufficient.

It's just a greyness in life I don't think there's much [health professionals] can do about it. Feels as though one is moaning when one's still alive. ....You feel you're bothering people... should really sort it out myself ( 75 years, married, stage I)

Despite this, men discussed various ways in which they felt they could have done with more emotional support, either from a psychologist or a specialist nurse who could also provide help with physical problems.

A bit of counselling, both before and after the treatment..... a psychologist really. But then you've got the physical problems that need to be coped with as well. One or the other or all 
rolled into one. One would expect that if there was a nurse counsellor, they'd be equipped to deal with both sides ( 75 years, married, stage I)

\section{Withdrawal (social/activity)}

Some men reported withdrawing from social situations and daily activities and becoming more sedentary and isolated ('I have become a bit of a loner', 67 years, married, stage IV). For some this appeared to be an element of their depressive state, while for others this was impacted by lower self-confidence, the physical impact of PCa and co-morbidities such as fatigue or loss of mobility, and was an unwanted change.

I am becoming a recluse, I mean I've got [ $x$ ] children and a load of grandchildren but I hardly ever see them. I'm inclined not to go out very much (65 years, married, stage I)

Figure 1 illustrates how men's perceptions of loss were central to their distress, and the four elements of loss were often interconnected. Men's perceptions seemed to be influenced by, and impacted upon, the maladaptive strategies they employed as well as the exacerbating factors that appeared to heighten vulnerability to distress.

\section{[insert figure 1]}

\section{Discussion}

The majority of men 18-42 months post PCa diagnosis in our wider sample did not exhibit psychological distress. Analysis of this subsample of 28 men in the context of the larger sample highlights how distressed men held stronger perceptions regarding a sense of loss, and how this was impacted by maladaptive coping strategies, as shown in our conceptual model (see Figure 1). Our findings demonstrate that two key elements of illness perceptions theory, illness consequences and control, (Leventhal et al., 2016) seemed to influence distress in men with PCa. Men's sense of loss regarding the negative impact to self, functioning and relationships is in line with research showing that perceptions of an illness having considerable consequences and symptoms are related to greater distress (Richardson et al., 2017), as are perceptions of having low control over illness (Richardson et al., 2017). Loss of self (Charmaz, 1995), has frequently been reported by individuals with chronic illness and adapting to a changed self, particularly to loss of confidence is a crucial part of recovery from cancer (Foster \& Fenlon, 2011). This was evidently a struggle for distressed men in our subsample. Our findings illustrate that men with distress might experience greater biographical disruption (Bury, 1982) and threat to their identities, and a greater struggle to overcome these, than non-distressed men in the wider sample.

Our conceptual model (figure 1) may be useful for understanding distress in people with other cancers. Previous work has indicated some similarity in themes such as loss with individuals with head and neck cancer (Lang, France, Williams, Humphris, \& Wells, 2013) as well as rumination and low social support in women with breast cancer exhibiting persistent distress (Lam et al., 2017). Many of the other exacerbating factors identified, such as co-morbidities and ADT treatment have also been previously associated with distress (Chambers et al., 2017; Nead et al., 2017; Wilding et al., 2019). Men who were younger, unpartnered or those with financial problems have also been shown to be particularly vulnerable to distress (Chambers et al., 2017; Collaço et al., 2019; Matheson et al., 2017). 
Our findings highlight that distressed men's strategies for coping, including avoidance, concealment and social withdrawal, may be linked to mental health and wellbeing issues. While we cannot be clear in many cases whether the distress preceded their PCa diagnosis or not, it appears that the subsample of distressed men were more likely than the main sample to adhere to dominant masculine ideals (Cecil et al., 2010). Comparisons with our main sample of non-distressed men suggest that these coping strategies appeared to sometimes be problematic. This confirms previous work suggesting that strategies of concealment, stoicism and avoidance can contribute to negative adjustment, information deficits and social isolation in men with cancer (Brunton, Booker, \& Molassiotis, 2012; Matheson et al., 2016). These strategies are also problematic if used excessively or rigidly, as they leave men vulnerable by being less able to access support networks (Bilsker et al., 2018). This is echoed previously in wider mental health research, as rigidity in men's coping and identities, in terms of hegemonic masculine scripts, has been theorised to explain why older men of European-descent are particularly vulnerable to suicide (Canetto, 2015). Further research in larger samples is required to quantify whether this is a significant moderator of distress in men with PCa. Our findings are also in line with research that demonstrates the importance of flexibility surrounding masculine identity (Spendelow et al., 2017). Approaches such as mindfulness based cognitive-behavioural interventions (Chambers et al., 2016; Kabat-Zinn, 2013)might promote psychological flexibility and reduce rumination on negative thoughts, shown previously to worsen distress (Williams \& Kuyken, 2018). However, it is unclear whether such interventions would be acceptable to this population, so future studies are needed.

\section{Implications for nursing}

Figure 1 offers a framework to aid nurses' understanding of which individuals may be particularly vulnerable to distress and we also highlight ways that men might be better supported (see Box 2). Screening for distress at clinical appointments might be useful if followed by enhanced discussions of psychosocial concerns (Meijer et al., 2013; Schuurhuizen et al., 2018; Smith, Loscalzo, Mayer, \& Rosenstein, 2018), which evidence suggests can improve well-being. The distress thermometer tool has been shown to be an acceptable screening tool in men with PCa (Chambers, Zajdlewicz, Youlden, Holland, \& Dunn, 2014). Nurse navigation targeted at distressed women with breast cancer indicated promising improvements in psychological health (Mertz et al., 2017), yet there is a need for studies with men with PCa, which should be the focus of further research. Tailored holistic needs assessments (HNA) would also enable nurses to identity those who have ongoing or unresolved physical problems that might be related to distress. Online HNAs for men with PCa, currently being trialled, might also have the potential to help men overcome barriers to talking about psychological concerns (Nanton et al., 2017).

Participants described how they wanted someone to take time to listen to them and provide reassurance. A simple approach such as facilitating discussions with a knowledgeable and empathetic nurse can lead men to feel more emotionally supported, as shown in an evaluation of a psycho-educational telephone intervention for men with PCa (Watson et al., 2018). The importance of targeting such interventions at men with greater need has been highlighted (Watson et al., 2018). Discussions during follow-up appointments that routinely ask men about their psychological health in addition to any ongoing or unresolved physical health issues, as well as follow-up telephone discussions, might therefore be useful. Nurses can support men with distress to adapt and adjust to changes in their sexual functioning, masculinity, confidence and self-identity by sign-posting them 
to relevant and available services that help meet their needs. Online mental health resources might be useful for nurses working in psycho oncology (International Psycho Oncology Society, 2019). Specialist cancer nurses are well positioned to counsel and help unravel the complex psychological concerns that men with PCa may face and can provide a gateway to other psychological and specialist services. These services include sexual rehabilitation clinics for erectile dysfunction, oncology rehabilitation clinics to improve incontinence issues, and community groups and local charities offering support. Nurse led clinics during and after treatment for PCa could also provide advice around stress management, exercise, wellbeing and staying active and could provide a forum for peer to peer social interaction and support, either through face-to-face meetings or online forums (Huber et al., 2018). Peer support interventions have been shown to be effective (Newby, Graff, Ganzini, \& McDonagh, 2015), so nurses could encourage men to utilise their social networks and facilitate peer support such as buddy systems, if appropriate. Individuals who experience loss of self-confidence might find it difficult to access support (Foster et al., 2015). Therefore, interventions that promote patient empowerment to seek support are warranted, particularly for hard-to-reach groups, such as men who avoid help seeking, Black and Minority Ethic (BME) men or unpartnered men who might be particularly isolated (Matheson et al., 2017; Rivas et al., 2016). The lack of studies addressing vulnerable and high need individuals with cancer has been highlighted recently, so further research is needed (Crawford-Williams et al., 2018).

Interventions that incorporate peer support, cognitive behavioural therapy (CBT) as well as tailored supportive care, were shown to reduce distress in men with PCa (Crawford-Williams et al., 2018). Nurses are well placed to identify which individuals with cancer might benefit from CBT (Daniels, 2015) or counselling services, and could refer particularly vulnerable men for specialist support, as required.

\section{Box 2: Recommendations for support for men with PCa}

- Assess men with PCa using appropriate distress screening tools/ holistic needs assessment at follow-up appointments, to identity those who have ongoing or unresolved psychological and/or physical problems.

- Support men with distress to adapt and adjust to changes in their sexual functioning, masculinity, confidence and self- identity.

- Guide men to psychological or rehabilitation services, as appropriate, including psychological therapies, cancer charities, sexual dysfunction clinics or physiotherapy services.

- Offer men with distress additional post-treatment follow-up where required and provide followup information and emotional support for men who wish to receive it, regarding management of physical and psychological concerns.

- Educate men about ways to improve wellbeing, such as stress management techniques including mindfulness and other activities such as exercise (or refer them to an appropriately trained professional)

- Assess men' social resources and support networks, and facilitate peer support such as buddy systems, and sign post to community or online support groups.

\section{Limitations}

Telephone interviews were useful for eliciting sensitive information and were more feasible than face-to-face due to issues of distance; however we were not able to pick up on non-verbal cues. We did not collect quantitative data on whether men had received diagnoses or treatment for clinical 
depression. Measures of distress were generic rather than PCa specific, and were not diagnostic or screening tools; however this did capture all participants who discussed significant distress during interview. A disproportionate number of men in this sub-sample were younger and receiving ADT; however this highlights the vulnerability of these groups and how they could be supported better. It is possible that men closer to diagnosis might be more distressed and for different reasons, however our study provides a snapshot of the experiences of men 18-42 months post diagnosis. The gender of the interviewers ( 3 female, 1 male) may have influenced our findings, however we do not feel this is the case, and interviews were generally rich and approximately an hour in length. We had difficulty recruiting men from BME backgrounds $(n=2)$, so further research is warranted. There is also the potential for non-response bias, as men with distress may be more or less likely to volunteer to complete the survey and be interviewed.

\section{Conclusion}

A multi-faceted theme of loss was magnified in men with psychological distress at least 18 months following PCa diagnosis. Relatively simple ways that nurses might identify and support such individuals are highlighted. Screening to identify those with distress is warranted. In order to alleviate distress, nurse or peer-led support could provide greater emotional support, through providing more time and reassurance, supporting with ongoing physical impacts, giving men opportunities to talk and signposting to psychological or rehabilitation services, where appropriate.

\section{Acknowledgements}

The Life After Prostate Cancer Diagnosis study was funded by the Movember Foundation, in partnership with Prostate Cancer UK, as part of the Prostate Cancer Outcomes programme, grant number BO26/MO. The authors thank all the men who responded to the survey. We acknowledge the following people for their contribution to the development, setting up and running of the study: Rebecca Mottram, Majorie Allen, Heather Kinnear, Conan Donnelly, Oonagh McSorley, Victoria Cairnduff, Linda Roberts, Adrian Slater, Picker Institute Europe, the LAPCD User Advisory Group and Clinical and Scientific Advisory Group. We would particularly like to thank Paul Jordan, Alistair Graham and John Keenan for their comments on the manuscript. This study is based in part on information collected and quality assured by the National Cancer Registration and Analysis Service (part of Public Health England), the Northern Ireland Cancer Registry, the Welsh Cancer Intelligence \& Surveillance Unit and the Scottish Cancer Registry (part of the Public Health \& Intelligence Unit of NHS National Services Scotland).The work of cancer registries uses data provided by patents and collected by health services as part of their care and support.

Conflict of Interest statement: The authors declare that they have no conflicts of interest.

\section{References}

Allemani, C., Weir, H. K., Carreira, H., Harewood, R., Spika, D., Wang, X. S., . . Group, C. W. (2015). Global surveillance of cancer survival 1995-2009: analysis of individual data for 25,676,887 patients from 279 population-based registries in 67 countries (CONCORD-2). The Lancet, 385(9972), 977-1010. doi:10.1016/S0140-6736(14)62038-9

Bilsker, D., Fogarty, A. S., \& Wakefield, M. A. (2018). Critical Issues in Men's Mental Health. The Canadian Journal of Psychiatry, 63(9), 590-596. 
Blomberg, K., Wengstrom, Y., Sundberg, K., Browall, M., Isaksson, A. K., Nyman, M. H., \& LangiusEklof, A. (2016). Symptoms and self-care strategies during and six months after radiotherapy for prostate cancer - Scoping the perspectives of patients, professionals and literature. Eur J Oncol Nurs, 21, 139-145. doi:10.1016/j.ejon.2015.09.004

Bray, F., Ferlay, J., Soerjomataram, I., Siegel, R. L., Torre, L. A., \& Jemal, A. (2018). Global cancer statistics 2018: GLOBOCAN estimates of incidence and mortality worldwide for 36 cancers in 185 countries. CA: a cancer journal for clinicians, 68(6), 394-424. doi:10.3322/caac.21492

Brunton, L., Booker, J., \& Molassiotis, A. (2012). Making sense of symptoms in men with prostate cancer: a longitudinal qualitative exploration. International Journal of Urological Nursing, 6(3), 107-114. doi:10.1111/j.1749-771X.2012.01150.x

Bury, M. (1982). Chronic illness as biographical disruption. Sociology of Health \& IIIness, 4(2), $167-$ 182. doi:10.1111/1467-9566.ep11339939

Canetto, S. S. (2015). Suicide: Why Are Older Men So Vulnerable? Men and Masculinities, 20(1), 4970. doi:10.1177/1097184X15613832

Cecil, R., Mc Caughan, E., \& Parahoo, K. (2010). 'It's hard to take because I am a man's man': an ethnographic exploration of cancer and masculinity. Eur J Cancer Care, 19(4), 501-509.

Chambers, S. K., Foley, E., Clutton, S., McDowall, R., Occhipinti, S., Berry, M., . . Smith, D. P. (2016). The role of mindfulness in distress and quality of life for men with advanced prostate cancer. Quality of Life Research, 25(12), 3027-3035. doi:10.1007/s11136-016-1341-3

Chambers, S. K., Ng, S. K., Baade, P., Aitken, J. F., Hyde, M. K., Wittert, G., . . Dunn, J. (2017). Trajectories of quality of life, life satisfaction, and psychological adjustment after prostate cancer. Psycho-Oncology, 26(10), 1576-1585. doi:10.1002/pon.4342

Chambers, S. K., Zajdlewicz, L., Youlden, D. R., Holland, J. C., \& Dunn, J. (2014). The validity of the distress thermometer in prostate cancer populations. Psycho-Oncology, 23(2), 195-203. doi:10.1002/pon.3391

Charmaz, K. (1995). The body, identity, and self: Adapting to impairment. Sociological Quarterly, 36(4), 657-680.

Clarke, A. L., Roscoe, J., Appleton, R., Parashar, D., Muthuswamy, R., Khan, O., . . Nanton, V. (2019). Promoting integrated care in prostate cancer through online prostate cancer-specific holistic needs assessment: a feasibility study in primary care. Supportive Care in Cancer. doi:10.1007/s00520-019-04967-y

Collaço, N., Wagland, R., Alexis, O., Gavin, A., Glaser, A., \& Watson, E. K. (2019). The challenges on the family unit faced by younger couples affected by prostate cancer: A qualitative study. Psycho-Oncology, 28(2), 329-335. doi:10.1002/pon.4944

Crawford-Williams, F., March, S., Goodwin, B. C., Ralph, N., Galvão, D. A., Newton, R. U., . . Dunn, J. (2018). Interventions for prostate cancer survivorship: A systematic review of reviews. Psycho-Oncology, 27(10), 2339-2348. doi:10.1002/pon.4888

Daniels, S. (2015). Cognitive behavior therapy for patients with cancer. Journal of the advanced practitioner in oncology, 6(1), 54.

Downing, A., Wright, P., Hounsome, L., Selby, P., Wilding, S., Watson, E., . . Butcher, H. (2018). Quality of life in men living with advanced and localised prostate cancer: A United Kingdom population-wide patient-reported outcome study of 30,000 men. Lancet Oncology.

Downing, A., Wright, P., Wagland, R., Watson, E., Kearney, T., Mottram, R., .. Glaser, A. W. (2016). Life after prostate cancer diagnosis: protocol for a UK-wide patient-reported outcomes study. BMJ Open, 6(12), e013555. doi:10.1136/bmjopen-2016-013555

Ervik, B., Nordoy, T., \& Asplund, K. (2010). Hit by waves-living with local advanced or localized prostate cancer treated with endocrine therapy or under active surveillance. Cancer Nurs, 33(5), 382-389. doi:10.1097/NCC.0b013e3181d1c8ea [doi] 
Foster, C., Breckons, M., Cotterell, P., Barbosa, D., Calman, L., Corner, J., . . Smith, P. W. (2015). Cancer survivors' self-efficacy to self-manage in the year following primary treatment. Journal of Cancer Survivorship, 9(1), 11-19. doi:10.1007/s11764-014-0384-0

Foster, C., \& Fenlon, D. (2011). Recovery and self-management support following primary cancer treatment. British journal of cancer, 105, S21. doi:10.1038/bjc.2011.419

Fung, Y.-L., \& Chan, Z. C. Y. (2011). A systematic review of suicidal behaviour in old age: a gender perspective. Journal of Clinical Nursing, 20(15-16), 2109-2124. doi:10.1111/j.13652702.2010.03649.x

Gale, N. K., Heath, G., Cameron, E., Rashid, S., \& Redwood, S. (2013). Using the framework method for the analysis of qualitative data in multi-disciplinary health research. BMC Medical Research Methodology, 13, 117. doi:10.1186/1471-2288-13-117

Gentili, C., McClean, S., Hackshaw-McGeagh, L., Bahl, A., Persad, R., \& Harcourt, D. (2019). Body image issues and attitudes towards exercise amongst men undergoing androgen deprivation therapy (ADT) following diagnosis of prostate cancer. Psycho-Oncology, $O(0)$. doi:10.1002/pon.5134

Huber, J., Muck, T., Maatz, P., Keck, B., Enders, P., Maatouk, I., \& Ihrig, A. (2018). Face-to-face vs. online peer support groups for prostate cancer: a cross-sectional comparison study. Journal of Cancer Survivorship, 12(1), 1-9.

International Psycho Oncology Society. (2019). Multilingual Core Curriculum In Psycho-oncology. Retrieved from https://ipos-society.org/module/english

Kabat-Zinn, J. (2013). Full Catastrophe Living (Revised Edition): Using the Wisdom of Your Body and Mind to Face Stress, Pain, and IIIness: Random House Publishing Group.

Kessler, R. C., Andrews, G., Colpe, L. J., Hiripi, E., Mroczek, D. K., Normand, S. L., . . Zaslavsky, A. M. (2002). Short screening scales to monitor population prevalences and trends in non-specific psychological distress. Psychological Medicine, 32(6), 959-976. doi:10.1017/S0033291702006074

Klaassen, Z., Jen, R. P., DiBianco, J. M., Reinstatler, L., Li, Q., Madi, R., . . Terris, M. K. (2015). Factors associated with suicide in patients with genitourinary malignancies. Cancer, 121(11), 18641872. doi:10.1002/cncr.29274

Lam, W. W., Yoon, S. W., Sze, W. K., Ng, A. W., Soong, I., Kwong, A., .. Fielding, R. (2017). Comparing the meanings of living with advanced breast cancer between women resilient to distress and women with persistent distress: a qualitative study. Psycho-Oncology, 26(2), 255-261. doi:10.1002/pon.4116

Lang, H., France, E., Williams, B., Humphris, G., \& Wells, M. (2013). The psychological experience of living with head and neck cancer: a systematic review and meta-synthesis. Psycho-Oncology, 22(12), 2648-2663.

Leventhal, H., Phillips, L. A., \& Burns, E. (2016). The Common-Sense Model of Self-Regulation (CSM): A dynamic framework for understanding illness self-management. Journal of Behavioral Medicine, 39(6), 935-946.

Matheson, L., Boulton, M., Lavender, V., Protheroe, A., Brand, S., Wanat, M., \& Watson, E. (2016). Dismantling the present and future threats of testicular cancer: a grounded theory of positive and negative adjustment trajectories. Journal of Cancer Survivorship, 10(1), 194-205. doi:10.1007/s11764-015-0466-7

Matheson, L., Watson, E. K., Nayoan, J., Wagland, R., Glaser, A., Gavin, A., . . Rivas, C. (2017). A qualitative metasynthesis exploring the impact of prostate cancer and its management on younger, unpartnered and gay men. European Journal of Cancer Care (Engl), 26(6). doi:10.1111/ecc.12676

McCaughan, E., Prue, G., Parahoo, K., Mcllfatrick, S., \& McKenna, H. (2011). Exploring and comparing the experience and coping behaviour of men and women with colorectal cancer at diagnosis and during surgery. Journal of Advanced Nursing, 67(7), 1591-1600. 
Meijer, A., Roseman, M., Delisle, V. C., Milette, K., Levis, B., Syamchandra, A., . . Coyne, J. C. (2013). Effects of screening for psychological distress on patient outcomes in cancer: a systematic review. Journal of Psychosomatic Research, 75(1), 1-17.

Mertz, B. G., Dunn-Henriksen, A. K., Kroman, N., Johansen, C., Andersen, K. G., Andersson, M., . . . Envold Bidstrup, P. (2017). The effects of individually tailored nurse navigation for patients with newly diagnosed breast cancer: a randomized pilot study. Acta Oncologica, 56(12), 1682-1689. doi:10.1080/0284186X.2017.1358462

Nanton, V., Appleton, R., Loew, J., Ahmed, N., Ahmedzai, S., \& Dale, J. (2017). Men don't talk about their health, but will they CHAT? The potential of online holistic needs assessment in prostate cancer. BJU international, 121(4), 494-496. doi:10.1111/bju.14114

National Institute For Health and Care Excellence. (2019). Prostate Cancer: Diagnosis and Management [NG131]. Retrieved from https://www.nice.org.uk/guidance/ng131

National Statistics. (2017). Health Survey for England 2016. Retrieved from http://healthsurvey.hscic.gov.uk/media/63763/HSE2016-Adult-wel-bei.pdf

Nead, K. T., Sinha, S., Yang, D. D., \& Nguyen, P. L. (2017). Association of androgen deprivation therapy and depression in the treatment of prostate cancer: A systematic review and metaanalysis. Urologic Oncology: Seminars and Original Investigations, 35(11), 664.e661664.e669. doi:10.1016/j.urolonc.2017.07.016

Newby, T. A., Graff, J. N., Ganzini, L. K., \& McDonagh, M. S. (2015). Interventions that may reduce depressive symptoms among prostate cancer patients: a systematic review and metaanalysis. Psycho-Oncology, 24(12), 1686-1693. doi:10.1002/pon.3781

$\mathrm{Ng}, \mathrm{C} .$, Kristjanson, L. J., \& Medigovich, K. (2006). Hormone ablation for the treatment of prostate cancer: the lived experience. Urology Nursing, 26(3), 204-212; discussion 215-208.

O'Shaughnessy, P. K., Ireland, C., Pelentsov, L., Thomas, L. A., \& Esterman, A. J. (2014). Impaired sexual function and prostate cancer: a mixed method investigation into the experiences of men and their partners. Journal of Clinical Nursing, 22(23-24), 3492-3502. doi:10.1111/jocn.12190 [doi]

10.1111/jocn.12190.

Oba, A., Nakaya, N., Saito-Nakaya, K., Hasumi, M., Takechi, H., Arai, S., \& Shimizu, N. (2017). Psychological distress in men with prostate cancer and their partners before and after cancer diagnosis: a longitudinal study. Japanese Journal of Clinical Oncology, 47(8), 735-742. doi:10.1093/jjco/hyx066

Paterson, C., Kata, S. G., Nandwani, G., Chaudhury, D. D., \& Nabi, G. (2017). Unmet supportive care needs of men with locally advanced and metastatic prostate cancer on hormonal treatment: a mixed methods study. Cancer Nursing, 40(6), 497-507.

Prochaska, J. J., Sung, H. Y., Max, W., Shi, Y., \& Ong, M. (2012). Validity study of the K6 scale as a measure of moderate mental distress based on mental health treatment need and utilization. International Journal of Methods in Psychiatry Research, 21(2), 88-97. doi:10.1002/mpr.1349

Punnen, S., Cowan, J. E., Chan, J. M., Carroll, P. R., \& Cooperberg, M. R. (2015). Long-term healthrelated quality of life after primary treatment for localized prostate cancer: results from the CaPSURE registry. European Urology, 68(4), 600-608. doi:10.1016/j.eururo.2014.08.074

QSR International Pty Ltd. (2016). NVivo qualitative data analysis Software: version 11.

Richardson, E. M., Schüz, N., Sanderson, K., Scott, J. L., \& Schüz, B. (2017). Illness representations, coping, and illness outcomes in people with cancer: a systematic review and meta-analysis. Psycho-Oncology, 26(6), 724-737. doi:10.1002/pon.4213

Rim, S. H., Yabroff, K. R., Dasari, S., Han, X., Litzelman, K., \& Ekwueme, D. U. (2019). Preventive care service use among cancer survivors with serious psychological distress: An analysis of the medical expenditure panel survey data. Preventive Medicine, 123, 152-159. doi:https://doi.org/10.1016/i.ypmed.2019.03.024 
Rivas, C., Matheson, L., Nayoan, J., Glaser, A., Gavin, A., Watson, E., \& Wagland, R. (Submitted). Men's transformations following a prostate cancer diagnosis and opportunities for intervention: a metaethnographic study.

Rivas, C., Matheson, L., Nayoan, J., Glaser, A., Gavin, A., Wright, P., .. . Watson, E. (2016). Ethnicity and the prostate cancer experience: a qualitative metasynthesis. Psycho-Oncology, 25(10), 1147-1156. doi:10.1002/pon.4222

Schildmeijer, K., Frykholm, O., Kneck, A., \& Ekstedt, M. (2019). Not a Straight Line-Patients' Experiences of Prostate Cancer and Their Journey Through the Healthcare System. Cancer Nurs, 42(1), E36-e43. doi:10.1097/ncc.0000000000000559

Schuurhuizen, C., Braamse, A., Beekman, A., Cuijpers, P., Van Der Linden, M., Hoogendoorn, A., .. . Dekker, J. (2018). Screening and stepped care targeting psychological distress in patients with metastatic colorectal cancer: The TES cluster randomized trial. Journal of Clinical Oncology, 36(15_suppl), 3560-3560. doi:10.1200/JCO.2018.36.15_suppl.3560

Smith, S. K., Loscalzo, M., Mayer, C., \& Rosenstein, D. L. (2018). Best Practices in Oncology Distress Management: Beyond the Screen. American Society of Clinical Oncology Educational Book(38), 813-821. doi:10.1200/EDBK_201307

Spendelow, J. S., Eli Joubert, H., Lee, H., \& Fairhurst, B. R. (2017). Coping and adjustment in men with prostate cancer: a systematic review of qualitative studies. Journal of Cancer Survivorship. doi:10.1007/s11764-017-0654-8

Stapleton, S., \& Pattison, N. (2015). The lived experience of men with advanced cancer in relation to their perceptions of masculinity: a qualitative phenomenological study. Journal of Clinical Nursing, 24(7-8), 1069-1078. doi:10.1111/jocn.12713

Stewart-Brown, S., Tennant, A., Tennant, R., Platt, S., Parkinson, J., \& Weich, S. (2009). Internal construct validity of the Warwick-Edinburgh Mental Well-being Scale (WEMWBS): a Rasch analysis using data from the Scottish Health Education Population Survey. Health and Quality of Life Outcomes, 7(1), 15. doi:10.1186/1477-7525-7-15

Tong, A., Sainsbury, P., \& Craig, J. (2007). Consolidated criteria for reporting qualitative research (COREQ): a 32-item checklist for interviews and focus groups. International Journal for Quality in Health Care, 19(6), 349-357. doi:10.1093/intqhc/mzm042

van Leeuwen, P. J., \& Schröder, F. H. (2010). Increased risk of suicide after prostate cancer diagnosis. Nature Reviews Urology, 7, 369. doi:10.1038/nrurol.2010.83

Watson, E., Shinkins, B., Frith, E., Neal, D., Hamdy, F., Walter, F., . . Rose, P. (2016). Symptoms, unmet needs, psychological well-being and health status in survivors of prostate cancer: implications for redesigning follow-up. BJU international, 117(6B), E10-19. doi:10.1111/bju.13122

Watson, E. K., Shinkins, B., Matheson, L., Burns, R. M., Frith, E., Neal, D., . . Rose, P. W. (2018). Supporting prostate cancer survivors in primary care: Findings from a pilot trial of a nurseled psycho-educational intervention (PROSPECTIV). European Journal of Oncology Nursing, 32, 73-81. doi:10.1016/j.ejon.2017.12.002

Watts, S., Leydon, G., Birch, B., Prescott, P., Lai, L., Eardley, S., \& Lewith, G. (2014). Depression and anxiety in prostate cancer: a systematic review and meta-analysis of prevalence rates. $B M J$ Open, 4(3).

Wenger, L. M., Oliffe, J. L., \& Bottorff, J. L. (2014). Psychosocial Oncology Supports for Men: A Scoping Review and Recommendations. American Journal of Men's Health. doi:10.1177/1557988314555361

Wilding, S., Downing, A., Wright, P., Selby, P., Watson, E., Wagland, R., ... Glaser, A. W. (2019). Cancer-related symptoms, mental well-being, and psychological distress in men diagnosed with prostate cancer treated with androgen deprivation therapy. Quality of Life Research. doi:10.1007/s11136-019-02212-x 
Williams, J. M. G., \& Kuyken, W. (2018). Mindfulness-based cognitive therapy: a promising new approach to preventing depressive relapse. British Journal of Psychiatry, 200(5), 359-360. doi:10.1192/bjp.bp.111.104745

World Health Organisation. (2014). Preventing Suicide: A Global Imperative. Retrieved from http://apps.who.int/iris/bitstream/10665/131056/8/9789241564878 eng.pdf

Wright, P., Wilding, S., Watson, E., Downing, A., Selby, P., Hounsome, L., ... Glaser, A. (2019). Key factors associated with social distress after prostate cancer: Results from the United Kingdom Life after Prostate Cancer diagnosis study. Cancer Epidemiology, 60, 201-207. doi:https://doi.org/10.1016/i.canep.2019.04.006

Zhao, G., Li, C., Li, J., \& Balluz, L. S. (2013). Physical activity, psychological distress, and receipt of mental healthcare services among cancer survivors. Journal of Cancer Survivorship, 7(1), 131-139.

Table 1. Participant characteristics

\begin{tabular}{|c|c|c|}
\hline Variable & Total N & \\
\hline \multirow[t]{2}{*}{ Age } & Mean & Range \\
\hline & 65.9 & $46-87$ \\
\hline Age group & $\mathbf{N}$ & $\%$ \\
\hline$<55$ & 2 & 7.1 \\
\hline $55-64$ years & 10 & 35.7 \\
\hline $65-74$ years & 12 & 42.9 \\
\hline $75-84$ years & 1 & 3.6 \\
\hline $85+$ years & 3 & 10.7 \\
\hline \multicolumn{3}{|l|}{ Nation } \\
\hline England & 17 & 60.7 \\
\hline Wales & 7 & 25.0 \\
\hline Northern Ireland & 2 & 7.1 \\
\hline Scotland & 2 & 7.1 \\
\hline
\end{tabular}

Marital status 


$\begin{array}{lcc}\text { Married/civil partnership } & 19 & 67.9 \\ \text { In a relationship } & 3 & 10.7 \\ \text { Divorced or widowed } & 3 & 10.7 \\ \text { Single } & 3 & 10.7\end{array}$

\section{Sexual Orientation}

$\begin{array}{lll}\text { Heterosexual } & 24 & 85.7\end{array}$

$\begin{array}{lll}\text { Gay or bisexual } & 4 & 14.2\end{array}$

\section{Ethnicity}

White British

26

92.9

Black British

2

7.1

\section{Disease Stage}

1

12

42.9

2

0

0

3

5

17.9

4

6

21.4

Missing

5

17.9

\section{Number of Long Term Conditions}

0

1

2

3

4
9

6

4

5

4
32.1

21.4

14.2

17.9

14.2

Treatment* 
$\mathrm{EBRT}+\mathrm{ADT}$

RP only

ADT only

BT only

Surgery + ADT

AS or WW

Surgery + EBRT + ADT

EBRT + ADT + chemotherapy
21.4

*radical prostatectomy (RP), external beam radiotherapy (EBRT), brachytherapy (BT), adjuvant androgen deprivation therapy (ADT), active surveillance (AS), watchful waiting (WW)

Figure 1: Perceptions of Loss- A model of psychological distress experienced by men with PCa

\section{Psychological vulnerability: Exacerbating factors}

- $\quad$ Pre-existing conditions of greater significance (physical and psychological comorbidities)

- High burden of PCa and treatment

- Being alone and unsupported

- Being younger

- Having advanced PCa

- Feeling restricted (socially, financially, physically)

- Personality factors (e.g. tendency to be anxious or depressed)

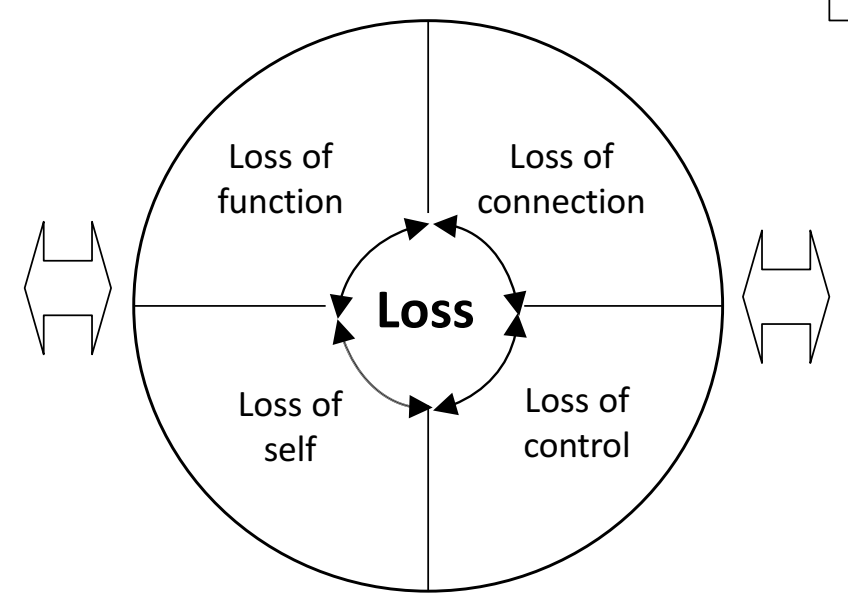

Maladaptive strategies for coping with distress

- Concealment and disclosure

- Avoidance of help seeking

- Withdrawal (social/activity) 


\section{Box 1: Topic guide}

Study Title: Life after prostate cancer diagnosis

Semi-structured interviews: Cross-sectional interviews (Men with Prostate Cancer)

The topic guide provides a number of questions which the interviewer might use to initiate discussion about a particular topic. However, the interviewer might revise the questions, or alter their order, in light of the interviewee's response to earlier questions.

1. Could you start by telling me what life has been like for you since your diagnosis of prostate cancer?

2. Could you tell me about the impact that prostate cancer has had on your life? Prompts:
a. Your quality of life?
b. Social life?
c. Relationships with spouse/family/peers?
d. Work life/voluntary roles?
e. Physical problems?
f. Finances and insurance?
g. Psychological/emotional?
h. Feelings towards body?
i. Future worries?
j. Sexual relationships and functioning (and impact on partner)?
k. Confidence?
I. Masculinity?
m. Coping strategies to manage?
n. Complementary therapies/diet/exercise?

3. Can you tell me about your experience of health and/or social services since your diagnosis?

Prompts:

a. What services used? (e.g. charities, counselling/psychologist, benefits advice, internet etc)

b. What worked well? Less well?

c. What done better?

d. How confident to manage?

e. How easy was it raising concerns? Talking to doctor/nurse etc?

f. How treated by Health professionals?

g. Decision making regarding treatment?

h. Experience of follow up? 
i. Prepared/aware of what to expect?

j. What support received for side effects or problems (e.g. psychological, physical, sexual problems)?

k. What information received for side effects or problems (e.g. psychological, physical, sexual problems)?

I. Accessed any other resources to help cope? (e.g. specialist nurse, general practitioner, incontinence clinic, sexual clinic, websites, booklets etc.)

m. More support or information needed at any point?

n. Involvement of your general practitioner (GP), in terms of information, support, satisfaction?

o. Confidence to manage PCa and its effects?

4. Are there any things you would change about the care and support you have received from health and/or social services and staff? Prompts:

a. Additional services?

b. What services could be put in place in future?

c. Alternative models of follow up (e.g. nursing, telephone vs face to face, remote follow up, hospital vs primary care based)

5. Can you tell me about the support you have had from sources other than health services? Prompts:
a. How has partner helped you to cope?
b. How has PCa impacted on partner/wife/family?
c. Peer support from other men with $\mathrm{PCa}$
d. Support groups?

6. Can you tell me about any other problems or issues you have had to deal with alongside the impact of prostate cancer?

Prompts:
a. Important aspect of life? Any changes at all?
b. Impact of PCa in relation to other things that have happened (e.g. other life events, comorbidities and impact of these)?
c. Positive outcomes?
d. How do you feel about having PCa at this point in your life?

7. Is there anything else you would like to add that I haven't asked you but which you think is important, or anything else you think l've missed? 


\section{LAPCD Study Coding framework}

\section{Care (Quality and Process)}

1.1. Continuity of care:

1.2.1. Consultants

1.2.2. Cancer nurse specialists/nurses

1.2.3. $\underline{G S}$

1.2.4. $\underline{\text { Other, }}$

1.3. Care during treatment

1.4. Follow-up and Discharge from treatment

1.5. Attitudes towards the NHS.

1.6. Healthcare delivery issues

1.7. Improvement suggestions

1.8. Views towards alternative models of follow-up care (use the following sub-codes):

1.8.1. Nurse-led

1.8.2. Remote (phone, skype, mail)

1.8.3. Patient triggered

1.8.4. Computerised questionnaires

\section{Cancer and its treatment}

2.1. Treatment decision making

2.1.2. $C A M$

2.2. Contextual knowledge of/beliefs towards PCa and treatment

2.3. Access and awareness

\section{Impact of disease and treatments}

3.1. Monetary and work implications

3.2. Social (use the following sub-codes):

3.2.1. Activities with other people

3.2.2. Life before $\mathrm{PCa}$ diagnosis

3.2.3. Social life

3.2.4. Feeling isolated

3.3. Dealing with change to identity (use the following sub-codes):

3.3.1. Masculinities

3.3.2. Body image

3.3.3. Life transitions

3.3.4. Other changed identity

3.4. Physical functioning issues from the cancer or its treatment, Physical impact

3.4.1. Sexual functioning, including $E D$

3.4.2. $\underline{U I}$

3.4.3. Bowel movements

3.4.4. Other physical symptoms

3.5. Feeling normal

3.6. Practical strategies/practical adjustment to treatment effects

3.7. Dealing with complications as a result of cancer treatment

3.8. The future

3.9. Lifestyle changes

3.10. Co-morbidities 
4.2. Communication with HCPs

4.3. Communication, and disclosure to sexual partners

4.4. Disclosure with others outside healthcare

4.5. $\quad$ Feeling prepared

4.6. Seeking or receiving support from HCPs

4.7. Seeking or receiving support from others in their informal networks

4.8. Information seeking

4.9. External sources of professional help.

4.10. Raising PCA awareness/Support from other men with PCa

4.10.1. Partners and significant others (children, families)

4.10.2. Other men

4.10.3. $\underline{P C S G S}$

\section{Coping and emotions}

5.1. Experiencing of emotions

5.2. Psychological strategies to cope with physical, relationships and social issues

5.3. Appraisals

5.4. Spirituality

5.5. (Dealing with) Other life issues

6. Diagnosis, determining or revisiting prognosis and impact of these

6.1. How diagnosis was done

6.2. Emotional impact/feelings around diagnostic and monitoring delays

6.3. Cognitive impact of diagnostic period

6.4. Impact of prognosis

6.5. Prognostic tests and prognosis expectations

\section{Partner}

7.1. Caring for the man

7.2. Differences between partner and man

7.3. The intimate relationship

7.3.1. MEN:

7.3.2. Partners 